\title{
Two-photon based imaging reveals mechanisms of tissue damage
}

\author{
Mohamed M. M. Hashem ${ }^{1}$
}

Received: 27 September 2018 / Accepted: 16 October 2018 / Published online: 7 November 2018

(c) Springer-Verlag GmbH Germany, part of Springer Nature 2018

In the recent issue of Hepatology, Ahmed Ghallab and colleagues from Dortmund University published an article, where they visualize the key event leading to bile infarcts, rupture of the apical hepatocyte membrane in individual hepatocytes of cholestatic livers (Ghallab et al. 2018). A central technique in this study is intravital two-photon microscopy. This technique allows imaging of intact organs in living anaesthetized mice. Recently, the method has been optimized by a well-matched combination of infrared lasers, specific long-distance objectives with high numerical aperture and very sensitive GaAsP detectors (Reif et al. 2017; Köppert et al. 2018). This allows resolution close to the theoretically possible $200 \mathrm{~nm}$. Therefore, bile canaliculi which have diameters ranging between 500 and $2000 \mathrm{~nm}$ (Hammad et al. 2014) can be visualized by this method. Similarly important is that fast sequences in the millisecond range can be recorded. Therefore, it was possible for the first time to record the fast process of apical membrane rupture. Initially, the local bile canaliculus swells and then suddenly ruptures, leading to regurgitation of the toxic canalicular bile acids into the adjacent hepatocyte. Interestingly, this isolated event with only one ruptured hepatocyte leads to a kind of domino effect where neighboring hepatocytes are also affected, leading to a growing necrotic region that accumulates bile acids, the so-called 'bile infarct'. This bile infarct differs from infarcts in other organs, where a localized area of dead tissue has been deprived of its blood supply; in liver, bile infarcts are not formed because of limited oxygen but due to bile leakage. The intravital imaging of Ghallab et al. (2018) now elucidates how exactly this pathological process is triggered.

Cholestasis represents an intensively studied field of research in toxicological sciences (Starokozhko et al. 2017; Miszczuk et al. 2015; Toledo et al. 2017; Vinken et al. 2017;

Mohamed M. M. Hashem

hashemm41@yahoo.com

1 Pharmacology Department, Faculty of Veterinary Medicine, Cairo University, Cairo, Egypt
Leist et al. 2017). The biliary tract has been shown to consist of three anatomical domains that respond differently to cholestasis (Vartak et al. 2016): large ducts widen their diameters, interlobular ducts respond by branching and looping thereby forming a denser mesh, while the most upstream domain, the bile canaliculi, become wider and form spiny protrusions into hepatocytes (Vartak et al. 2016; Jansen et al. 2017). Much effort has been invested in developing in vitro test systems for cholestasis (Deharde et al. 2016; Luckert et al. 2017; Frey et al. 2014; Godoy et al. 2013; Reif et al. 2015) and transcriptomic signatures have been identified (Parmentier et al. 2017; Ghallab 2017; Stöber 2016; Grinberg et al. 2014). However, so far the observation of Ghallab et al. (2018) that rupture of apical hepatocyte membranes is a key event, causing bile infarcts has only been possible to be demonstrated in vivo.

\section{Compliance with ethical standards}

Conflict of interest The author declares that he has no conflict of interest.

\section{References}

Deharde D, Schneider C, Hiller T, Pratschke J, Zeilinger K, Damm G et al (2016) Bile canaliculi formation and biliary transport in 3D sandwich-cultured hepatocytes in dependence of the extracellular matrix composition. Arch Toxicol 90(10):2497-2511

Frey O, Misun PM, Fluri DA, Hengstler JG, Hierlemann A (2014) Reconfigurable microfluidic hanging drop network for multitissue interaction and analysis. Nat Commun 5:4250. https://doi. org/10.1038/ncomms 5250

Ghallab A (2017) Highlight report: metabolomics in hepatotoxicity testing. EXCLI J 16:1323-1325

Ghallab A, Hofmann U, Sezgin S, Jansen PLM, Hengstler JG, Reif $\mathrm{R}$ et al (2018) Bile micro-infarcts in cholestasis are initiated by rupture of the apical hepatocyte membrane and cause shunting of bile to sinusoidal blood. Hepatology. https://doi.org/10.1002/ hep.30213 (Epub ahead of print)

Godoy P, Hewitt NJ, Albrecht U et al (2013) Recent advances in 2D and $3 \mathrm{D}$ in vitro systems using primary hepatocytes, alternative hepatocyte sources and non-parenchymal liver cells and their use 
in investigating mechanisms of hepatotoxicity, cell signaling and ADME. Arch Toxicol 87(8):1315-1530

Grinberg M, Stöber RM, Edlund K, Leist M, Rahnenführer J, Hengstler JG et al (2014) Toxicogenomics directory of chemically exposed human hepatocytes. Arch Toxicol 88(12):2261-2287

Hammad S, Hoehme S, Friebel A, Gebhardt R, Drasdo D, Hengstler JG et al (2014) Protocols for staining of bile canalicular and sinusoidal networks of human, mouse and pig livers, three-dimensional reconstruction and quantification of tissue microarchitecture by image processing and analysis. Arch Toxicol 88(5):1161-1183

Jansen PL, Ghallab A, Vartak N, Reif R, Schaap FG, Hampe J, Hengstler JG (2017) The ascending pathophysiology of cholestatic liver disease. Hepatology 65(2):722-738

Köppert S, Büscher A, Babler A et al (2018) Cellular clearance and biological activity of calciprotein particles depend on their maturation state and crystallinity. Front Immunol 9:1991. https://doi. org/10.3389/fimmu.2018.01991

Leist M, Ghallab A, Graepel R, Kroese D, van de Water B, Hengstler JG et al (2017) Adverse outcome pathways: opportunities, limitations and open questions. Arch Toxicol 91(11):3477-3505

Luckert C, Schulz C, Lehmann N, Braeuning A, Lampen A, Hessel $S$ et al (2017) Comparative analysis of 3D culture methods on human HepG2 cells. Arch Toxicol 91(1):393-406

Miszczuk GS, Barosso IR, Zucchetti AE, Sánchez Pozzi EJ, Roma MG, Crocenzi FA et al (2015) Sandwich-cultured rat hepatocytes as an in vitro model to study canalicular transport alterations in cholestasis. Arch Toxicol 89(6):979-990
Parmentier C, Couttet P, Wolf A, Bachellier P, Uteng M, Richert L et al (2017) Evaluation of transcriptomic signature as a valuable tool to study drug-induced cholestasis in primary human hepatocytes. Arch Toxicol 91(8):2879-2893

Reif R, Karlsson J, Günther G, Kaye PM, Hengstler JG, Jirstrand M et al (2015) Bile canalicular dynamics in hepatocyte sandwich cultures. Arch Toxicol 89(10):1861-1870

Reif R, Ghallab A, Beattie L, Kuepfer L, Kaye PM, Hengstler JG et al (2017) In vivo imaging of systemic transport and elimination of xenobiotics and endogenous molecules in mice. Arch Toxicol 91(3):1335-1352. https://doi.org/10.1007/s00204-016-1906-5

Starokozhko V, Greupink R, van de Broek P, Ghimire S, de Graaf IAM, Groothuis GMM et al (2017) Rat precision-cut liver slices predict drug-induced cholestatic injury. Arch Toxicol 91(10):3403-3413

Stöber R (2016) Pathophysiology of cholestatic liver disease and its relevance for in vitro tests of hepatotoxicity. EXCLI J 15:870-871

Toledo FD, Basiglio CL, Barosso IR, Zucchetti AE, Sánchez Pozzi EJ, Roma MG et al (2017) Mitogen-activated protein kinases are involved in hepatocanalicular dysfunction and cholestasis induced by oxidative stress. Arch Toxicol 91(6):2391-2403

Vartak N, Damle-Vartak A, Richter B, Dahmen U, Hammad S, Hengstler JG et al (2016) Cholestasis-induced adaptive remodeling of interlobular bile ducts. Hepatology 63(3):951-964

Vinken M, Knapen D, Vergauwen L, Hengstler JG, Angrish M, Whelan M (2017) Adverse outcome pathways: a concise introduction for toxicologists. Arch Toxicol 91(11):3697-3707 